\title{
Epileptic seizures resulting from acute cerebral anoxia
}

\author{
D. MADISON ${ }^{1}$ AND E. NIEDERMEYER
}

\begin{abstract}
From the Neurology Service, Walter Reed General Hospital, Washington, D.C. and Division of Neurological Surgery, Johns Hopkins University School of Medicine, Baltimore, Md., U.S.A.
\end{abstract}

SUMMARY Five patients with acute anoxic episodes requiring resuscitation, with coma and development of epileptic manifestations are reported. Myoclonic types of seizures were predominantly seen in these cases. Rhythmical or burst-like generalized-synchronous spike discharges represented the most common EEG correlate of the epileptic activity. In one patient, a suppression-burst-like pattern was temporarily seen. The two youngest of the patients survived and there was remarkable recovery in spite of the persistence of myoclonic jerking. Stress is laid upon the distinction between tonic brain-stem release phenomena (with concomitant flat or featureless EEG tracings) and authentic epileptic activity in association with spike discharges in cerebral anoxia.

The occurrence of tonic seizures and opisthotonic posturing in states of acute cerebral anoxia is widely known and has been well documented by experimental studies (Noell and Kornmüller, 1944; Ward, Jr., 1947; Gellhorn and Heymans, 1948; Noell, 1948; Ajmone-Marsan and Fuortes, 1949; Gänshirt and Zylka, 1952). This type of tonic seizure is thought to be a release phenomenon of the brain-stem in a decerebrate state (Sherrington, 1898) and has been attributed to the interruption of afferent impulses to the bulbar suppressor area (Ward, Jr., 1947). Gastaut, Naquet, and FischerWilliams (1958) have laid emphasis upon the distinction between tonic anoxic attacks with flat or featureless electroencephalographic (EEG) tracings and authentic epileptic phenomena with their classical electroencephalographic concomitants in the cortex, basal ganglia, and diencephalic level.

This study deals only with 'true' epileptic manifestations resulting from cerebral anoxia. Convulsions after perinatal or early infancy anoxia and seizures as a late sequel of brain anoxia are not included.

There have been only scanty reports on acutely developing epileptic conditions in states of cerebral anoxia. The scarcity of reports on anoxic epilepsy is rather surprising, since many neurologists and electroencephalographers have seen such cases in recent years as we have learned from personal

${ }^{1}$ Present address: Neurology Service, Fitzsimons General Hospital, Denver, Col., U.S.A. communications. In a study on myoclonus, Swanson, Luttrell, and Magladery (1962) gave a brief account of myoclonic seizures secondary to anoxia. A thoughtful analysis of post-anoxic myoclonus was presented by Lance and Adams (1963) on the basis of four cases. These authors stressed the residual myoclonus ('intention myoclonus') after survival from the acute episode. Pampiglione and Harden (1968) investigated the EEG in children resuscitated after cardiac arrest and noted the occurrence of suppression-burst patterns in association with seizures.

There is some likelihood that, with greatly improved methods of resuscitation, there will be a considerable increase in the number of electroencephalograms performed in victims of cerebral anoxia. These theoretical and practical considerations should justify the following report.

\section{MATERIAL AND METHOD}

Five patients with anoxic epileptic seizures were observed during the past year; three of them were in the Johns Hopkins Hospital, and one in the Walter Reed Hospital; the remaining patient was treated elsewhere in the acute episode and subsequently sent to the John F. Kennedy Institute for Handicapped Children in Baltimore.

In each of these patients, several EEG tracings were carried out with eight, 10 , or 16 channel apparatuses. During the acute stage, most of the bedside EEG tracings were obtained with 10 electrodes, otherwise the International Electrode System (21 electrodes) was 
used with bipolar and referential recording techniques.

The clinical findings were analysed in each case. Necropsy was carried out in all of the three fatal cases, but only a brief résumé of the pathological findings will be given in this context.

\section{CASE 1}

This 22-year-old man was seen on 14 June 1968 at the Johns Hopkins Hospital emergency room because of difficulty with breathing. He had been well until the previous day when he developed a sore throat and laryngitis which progressed after several hours to stridor and dyspnoea. Endotracheal intubation was performed and he was admitted. When he reached the ward, he was noted to be agitated but well orientated and neurologically intact.

Shortly afterwards he became extremely confused and forcibly jerked out his endotracheal tube. When seen several seconds later, he was extremely dyspnoeic and combative, resisting all efforts to replace the airway. He lost consciousness after three to four minutes and an emergency tracheostomy was performed. During this procedure the patient developed a transient bradycardia with S-T segment depression. The electrocardiographic changes were suggestive of an anterior myocardial infarction and this was confirmed by elevation of SGOT to 410 units.

After this series of events, the patient was comatose and after a few hours he developed myoclonic jerking which occurred either spontaneously or secondary to sensory and especially noxious stimuli. During the next 48 hours the myoclonus increased in severity. All four extremities were synchronously and symmetrically involved and there was also participation of facial and truncal muscles. During this stage (on
17 June) the first EEG revealed almost continuous generalized-synchronous multiple spikes and spike- $Z$ wave-like discharges, in association with myoclonic jerking (Fig. 1a).

Over the next several weeks the patient regained consciousness and the myoclonic jerking gradually diminished. A second EEG (20 June) showed dis- $\square$ continuous spiking and the development of normal background activity. He made a slow but progressive $\frac{\rho}{\partial}$ recovery to the point where he could sit in a wheelchair and walk with assistance at the time of his discharge (14 August). However, he continued to have myoclonic jerks in combination with intention tremor; there was $\stackrel{0}{\rightarrow}$ also a marked degree of dysarthria. His EEG (Fig. 1b) showed small spikes with a maximum in the vertex area.

\section{CASE 2}

This 65-year-old man presented to the Walter Reed General Hospital emergency room on 20 November $\overrightarrow{-}$ 1967 with a history of acute severe chest pain and. dyspnoea. An electrocardiograph revealed marked S-T $\vec{\omega}$ segment elevation and he was admitted to the cardiac of intensive care unit. Thirty minutes later he had an episode of ventricular fibrillation with an associated generalized tonic convulsion and subsequent coma.

Resuscitation was begun immediately but the patient never regained consciousness. Throughout the furth $\bar{\theta} \omega$ course he had a flaccid quadriparesis with bilateral $\infty$ Babinski responses, and was totally unresponsive to की 1 stimuli. For several days after resuscitation he hæd tonic-clonic seizures with a predominant tonic comporent. An EEG was obtained 48 hours after admission and showed continuous rhythmical 2 to $3 / \mathrm{sec}$ activify with a definite spike component, most prominent $\vec{\theta}$ the frontal leads (Fig. 2). The seizure activity was co?

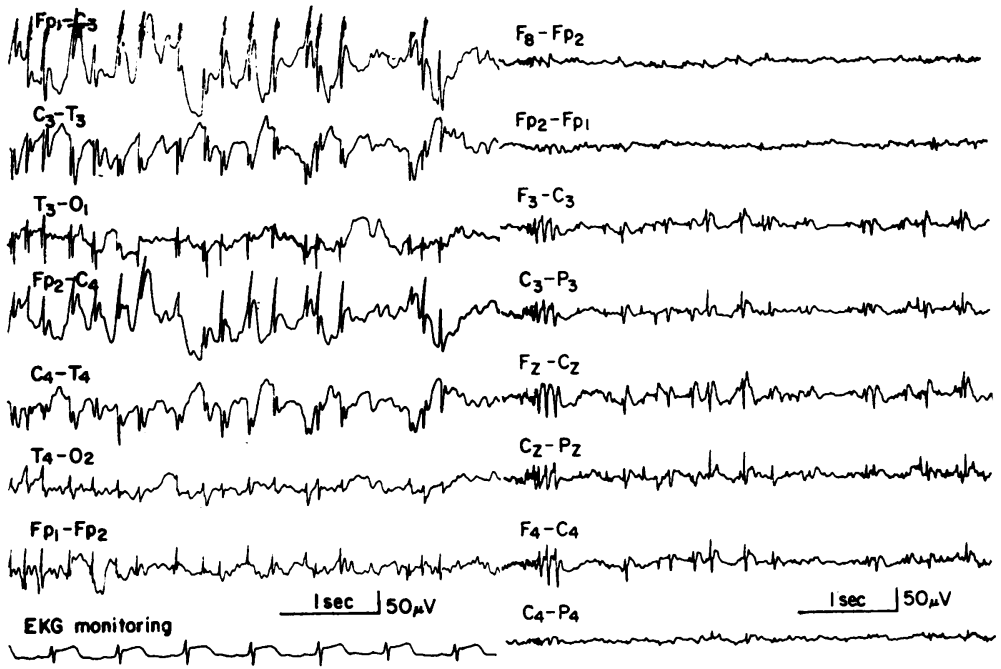

(a)
FIG. 1. Left: (a) Case 1, age 22 years; almost continuous generalized-synchronous spikes during post-anoxic coma. Right: (b) The same patient, two months later. Note a maximum of spikes over the vertex with spread into central and frontal leads (part of a 16 channel recording). 


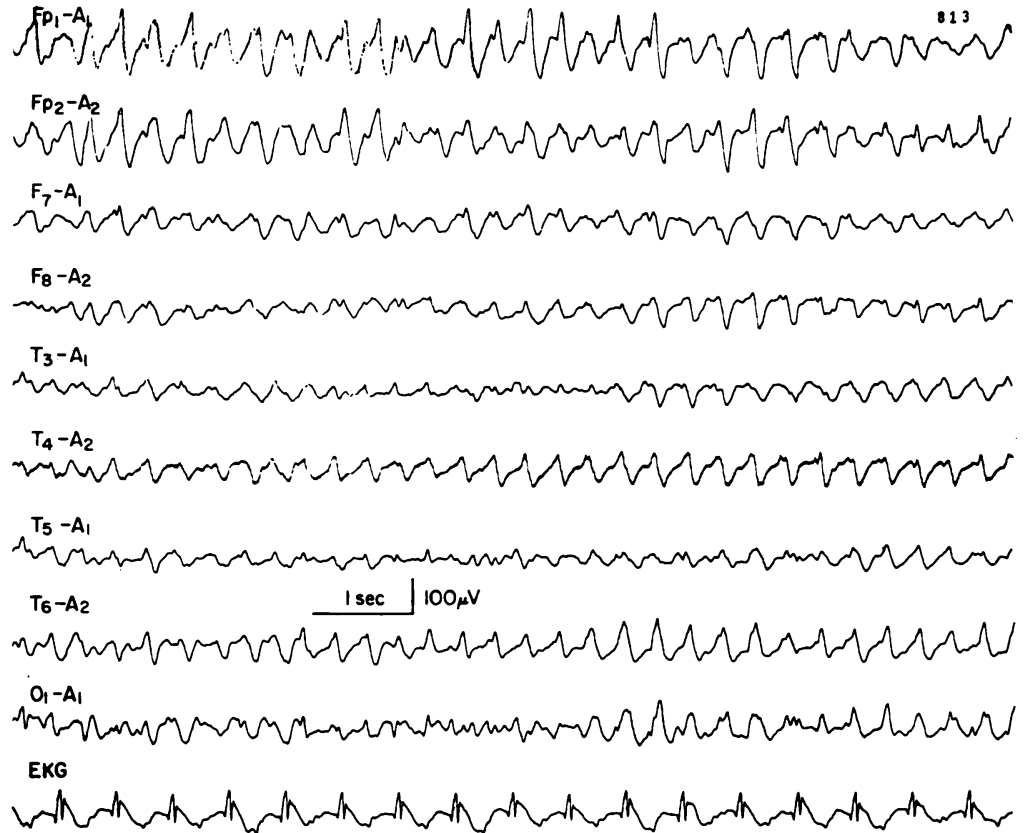

FIG. 2. Case 2, age 65 years. Continuous rhythmical 2-3/sec activity with a spiky component, most prominent in the frontal leads. trolled with intravenous sodium amylobarbitone and diphenylhydantoin.

The patient developed pneumonia and died on 26 December. The post-mortem examination of the brain showed typical cortical laminar necrosis, involving chiefly the layers 3 through 5 . The hippocampus showed (in Sommer's sector) pronounced loss of neurones with reactive gliosis. In multiple cerebellar section, there was a diffuse loss of Purkinje cells. Diffuse neuronal loss was also noted in the globus pallidus and putamen.

\section{CASE 3}

This 57-year-old woman was admitted to the Johns Hopkins Hospital on 18 November 1968, bəcause of severe dyspnoea. She had a history of acute and chronic bronchitis, asthma, emphysema, and cor pulmonale. Initially she was irritable and uncooperative but the neurological examination was otherwise unremarkable. She had continuing hypoxaemia despite various therapeutic measures and on 15 December she was intubated and placed on a respirator. The following morning she became comatose and had a brief convulsion. By late afternoon (16 December) she was alert and well orientated but later that evening the respirator misfunctioned and she began to have repeated generalized seizures. She became comatose and never awakened; she was totally unresponsive to all stimuli, areflexic, and flaccid.

On 17 December the patient developed myoclonic jerking. The first EEG was done on 18 December while sporadic myoclonic jerks synchronously occurred in all muscular segments. The EEG showed periods of electrical silence alternating with generalized-synchronous sharp waves of very high voltage, either isolated or occurring in groups of two or three discharges (Fig. 3). Only a small number of these discharges were accompanied by clinical myoclonus.

Nine further bedside EEG tracings were obtained between 19 December 1968 and 6 January 1969. On

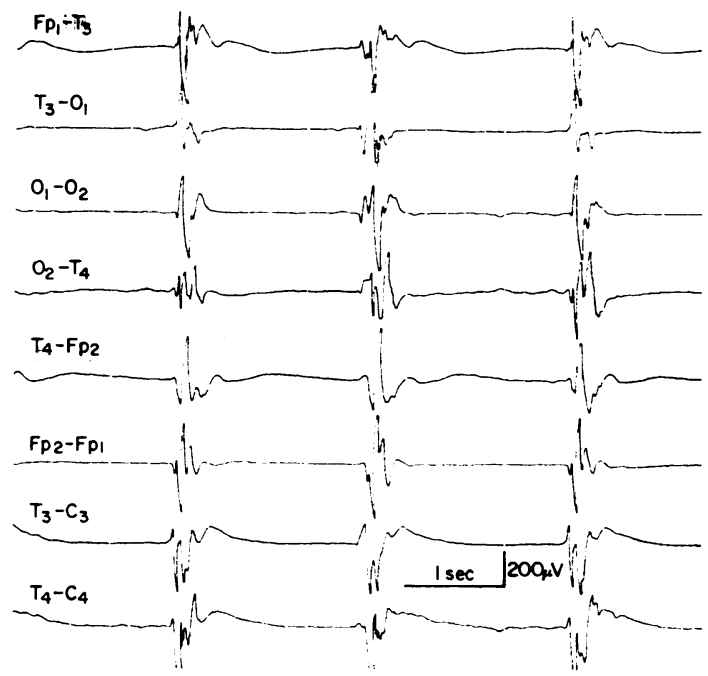

FIG. 3. Case 3, age 57 years. A complex and polyphasic type of generalized-synchronous sharp waves is rhythmically alternating with periods of near-flatness (suppressionburst-like pattern). 
23 December some improvement was noted: the previous suppression-burst-like pattern was associated with spindle-like 12-15/sec activity, while the generalizedsynchronous sharp discharges had changed into vertexwave-like potentials (Fig. 4). The suppression-burst character gradually disappeared and the last few records were disorganized and diffusely slow (Fig. 5). The patient remained on the respirator until her death from pneumonia on 9 January 1969.

Post-mortem examination revealed severe acute and chronic broncho-pulmonary disease including pneumonitis and lung abscess. Intracranially, there was moderate congestion of the meningeal vessels; the brain itself was macroscopically unremarkable. The microscopic examination showed an almost total Purkinje cell loss in the cerebellum. There was also a severe loss of hippocampal pyramidal cells involving not only Sommer's sector but the entire pyramidal cell layer. The cerebral neocortex, however, showed only moderate changes with mild focal neuronal loss.

\section{CASE 4}

This 68-year-old woman was admitted to the Johns Hopkins Hospital on 9 September 1968, with a one week history of vomiting. She had a history of previous surgery for closure of a perforating duodenal ulcer with complicating peritonitis, and had done poorly since that time, experiencing progressive weight loss and anorexia. On examination, she was cachectic, pale, dehydrated, and mildly disorientated. She had paranoid ideation and was at times, hallucinated. On the ward she refused to eat and accused the personnel of trying
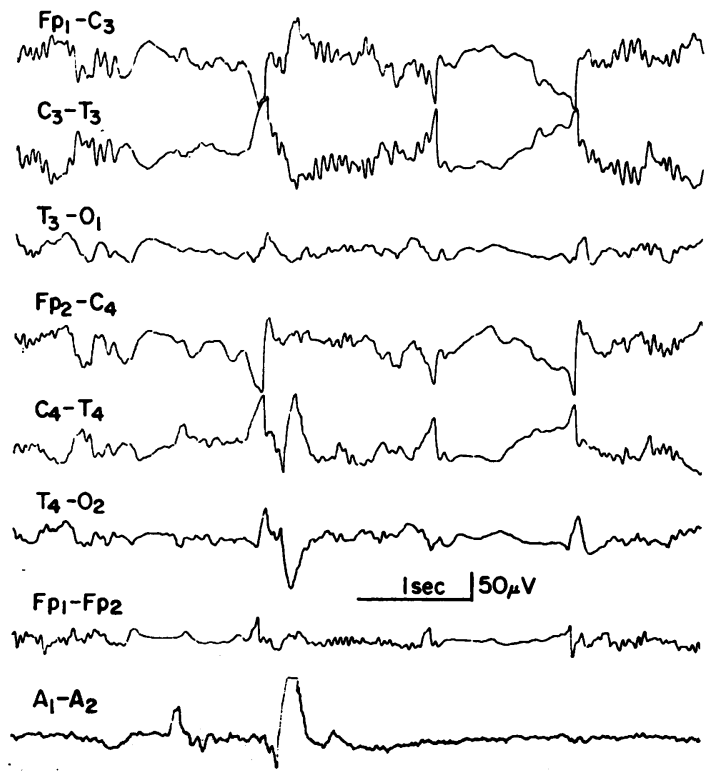

FIG. 4. The same patient (case 3), six days later. Note pronounced vertex waves with sleep spindles.

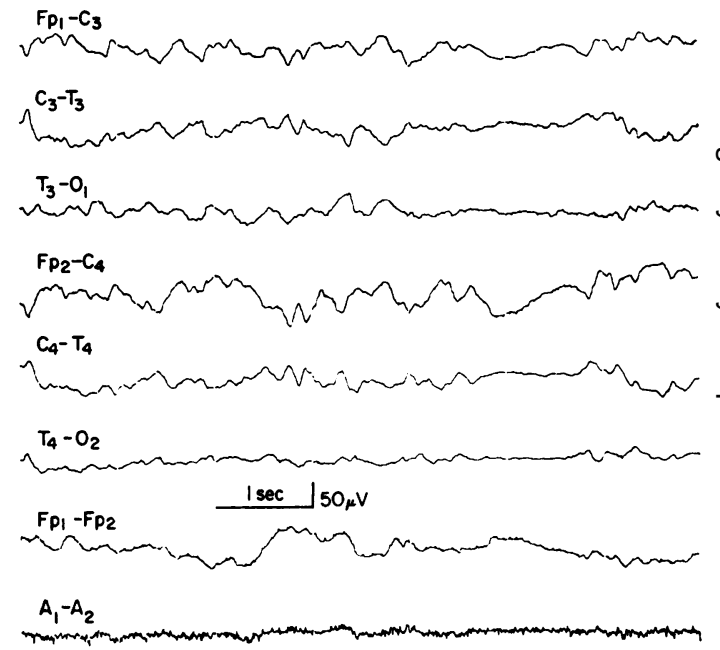

FIG. 5. The same patient (case 3), two weeks later. Diffuse irregular slowing has replaced previous paroxysmal patterns.

to poison her. An EEG performed on 11 Septemb was slightly abnormal because of excessive diffuge slow activity; the posterior alpha rhythm was fairly wêt preserved.

On 4 November, she underwent an exploratog laparotomy and was found to have numerous adhesiong, a duodenal ulcer, and cholecystitis. Appropriate surgical $\overrightarrow{0}$ measures were taken and she tolerated the procedufte 'surprisingly well' but continued to do poorly afterwards. On 17 November she vomited, aspirated gastric contents, and had a respiratory arrest followed by a cardiac arrest. Resuscitation was performed but she $\frac{\partial}{\partial}$ failed to regain consciousness and had numerous generalized myoclonic twitchings.

On 19 November her EEG showed continuous generalized-synchronous $2 \cdot 5-3 / \mathrm{sec}$ spike-wave-like activity with a central maximum (Fig. 6). At this time no myoclonic manifestations were present. The patient died on 21 November without ever regaining consciousness.

Necropsy revealed multiple pulmonary infarctions secondary to iliac vein thrombosis. The brain was not examined.

CASE 5

This $6 \frac{1}{2}$-year-old boy was well until 16 March 1968, ᄋ when he developed acute respiratory distress secondary to epiglottitis. On the way to the hospital he had a o respiratory arrest and failed to respond to mouth-tomouth resuscitation. When seen in the emergency room $N$ (of an outside hospital) about five minutes later, he was pulseless and had dilated fixed pupils. An endotracheal 0 tube was passed and with artificial respiration his cardiac $\underset{\omega}{N}$ activity returned, and the pupils became normally 


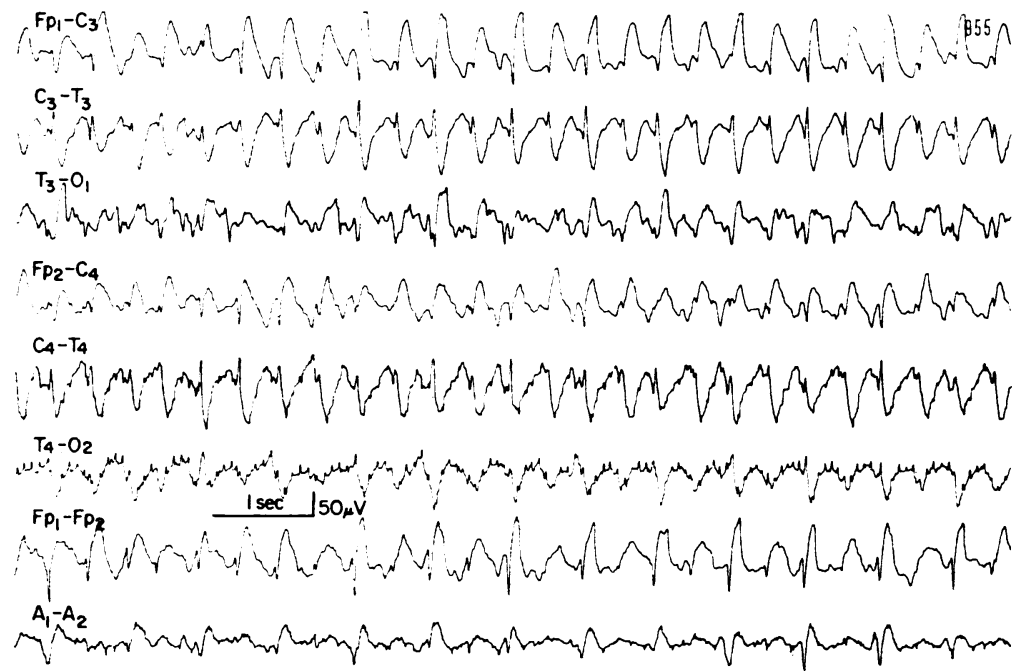

FIG. 6. Case 4, age 68 years. Generalized spike-wave-like activity with a bilateral central maximum of spike discharges.

reactive. However, the patient remained comatose. Several hours later he was responsive only to noxious stimuli and had episodes of decerebrate posturing as well as occasional generalized clonic activity.

On 18 March he was responding to verbal stimuli but on 20 March he became less responsive and had frequent seizures of an undetermined character. $\mathrm{He}$ remained unresponsive and on 23 March an EEG showed diffuse high voltage delta activity; no spikes were noted. Gradual improvement in the level of consciousness occurred during the following two weeks but he developed convulsions involving the left arm and leg.

The patient was transferred to the John F. Kennedy Institute for Handicapped Children on 24 April 1968. At that time he had frequent bilateral-synchronous myoclonic jerks of both upper extremities. The lower extremities were spastic and contracture formation had begun.

Ten EEG records were obtained at the Kennedy Institute. On 6 June 1968, various spike foci were noted; subclinical ictal episodes would rapidly change their focal origin. A maximum of spike-activity was seen over the right posterior quadrant.

In the further course, signs of cortical blindness were noted but this deficit gradually disappeared within several weeks. On 17 October, most spike discharges occurred in bilateral synchrony but with inconsistent and shifting asymmetries (Fig. 7). This type of EEG abnormality remained fairly stable in his last four tracings.

On 31 January 1969 he was discharged after having made a slow but impressive recovery. He could not walk but was able to to move around in a wheel chair. He still showed some degree of spastic paraparesis; sporadic myoclonic jerks and a mild choreatic dyskinesia were also present. His verbal Intelligence Quotient, however, was in the normal range.

\section{DISCUSSION}

There is no doubt that each of the patients had clinical and electroencephalographic epileptic seizure manifestations resulting from cerebral anoxia. Bilateral and synchronous myoclonus was the best documented and most commonly occurring type of seizure. The myoclonic activity involved all limbs as well as head and trunk muscles; sensory or auditory precipitation of jerking was occasionally noted.

This type of myoclonus was also reported by Swanson et al. (1962) and Lance and Adams (1963). No evidence of myoclonic seizures, however, was found in our second case; the attacks were described as predominantly tonic but the electroencephalographic demonstration of rhythmical slow activity with a definite generalized spike component would substantiate the authentic epileptic character of the seizures.

The EEG correlates of myoclonic manifestations showed marked variations in quantity ranging from a suppression-burst-like pattern with generalizedsynchronous spikes arising from a virtually flat background EEG (see Fig. 3) to spike-wave-like patterns (see Figs. 2 and 6). It is interesting to note (in case 3 ) how the spike discharges changed into repetitive vertex waves followed by spindle trains (Fig. 4). One is tempted to speculate that a gamut of exaggerated arousal responses might be present in anoxic myoclonus; the occasional presence of stimulus-sensitivity would support this view. Hal- 


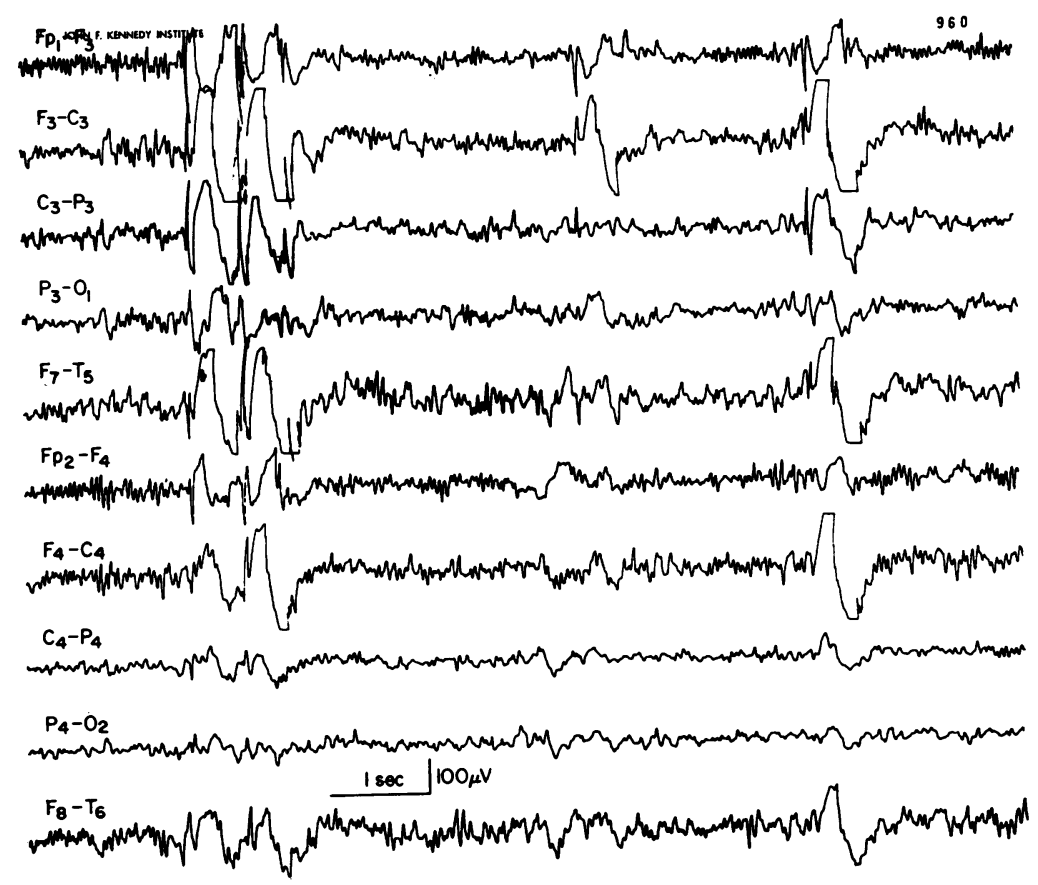

FIG. 7. Case 5, age $6 \frac{1}{2}$ years. This tracing was obtained seven months after the acute cerebral anoxic episode. Brief bursts of spike-wave discharges are seen, mainly over anterior areas with occasional shifting asymmetries.

liday (1967) has stressed the role of the reticular activating system and related arousal mechanisms in certain types of myoclonus.

When the anoxic catastrophe is survived, myoclonus may turn into a residual manifestation. Case 1 showed the characteristics of the 'intention myoclonus' reported by Lance and Adams (1963) who cautiously related this type of myoclonus to hypoxic damage of the cerebellum.

As to the pathophysiological substratum of anoxic epilepsy, it is reasonable to assume widespread neuronal damage. While complete suppression and destruction of cortical functions will lead to a decerebrate picture with a flat EEG and tonic spasms, a severe but incomplete type of cortical and subcortical damage could result in predominantly myoclonic epileptic attacks. Watson and Denny-Brown (1955) have postulated that 'a breakdown in synaptic resistance due to diffuse neuronal disease, particularly in subcortical structures, is responsible for the phenomenon of myoclonus'. This breakdown, however, appears to be more complex in the light of Halliday's (1967) extensive analysis.

\section{REFERENCES}

Ajmone-Marsan, C., and Fuortes, M. G. F. (1949). Electrographic study of the convulsant action of intravenously administered acetylcholine. Electroenceph. clin. Neurophysiol., 1, 283-290.
Gänshirt, H., and Zylka, W. (1952). Die Erholungsze्f am Warmblütergehirn nach kompletter Ischämie. Arch. Psychiat. Nervenkr., 189, 23-36.

Gastaut, H., Naquet, R., and Fischer-Williams, M. (195\&. The pathophysiology of grand mal seizures generalized from the start. J. nerv. ment. Dis., 127, 21-33.

Gellhorn, E., and Heymans, C. (1948). Differential actiôm of anoxia, asphyxia and carbon dioxide on normal and convulsive potentials. J. Neurophysiol., 11, 261-273.

Halliday, A. M. (1967). The electrophysiological study of myoclonus in man. Brain, 90, 241-284.

Lance, J. W., and Adams, R. D. (1963). The syndrome of intention or action myoclonus as a sequel to hypoxic $\mathbb{Q}$ encephalopathy. Brain, 86, 111-136.

Noell, W. (1948). Überlebens- und Wiederbelebenszeiten des Gehirns bei Anoxie. Arch. Psychiat. Nervenkr., 180, 687-712.

Noell, W., and Kornmüller, A. E. (1944). Zur Sauerstoffmangelwirkung auf die Hirnrinde. Eine bioelektrische Untersuchung. Pflügers Arch. ges. Physiol., 247, 685-712.

Pampiglione, G., and Harden, A. (1968). Resuscitation $\bar{\sigma}$ after cardiovascular arrest. Prognostic evaluation 3 of early electroencephalographic findings. Lancet, 1, 1261-1264.

Sherrington, C. S. (1898). Decerebrate rigidity, and reflex coordination of movements. J. Physiol. (Lond.), 22, 응 319-332.

Swanson, P. D., Luttrell, C. N., and Magladery, J. W. D (1962). Myoclonus-A report of 67 cases and review of the literature. Medicine (Baltimore), 41, 339-356.

Ward, A. A., Jr. (1947). Decerebrate rigidity. J. Neurophysiol., 10, 89-103.

Watson, C. W., and Denny-Brown, D. (1955). Studies of the mechanism of stimulus-sensitive myoclonus incw man. Electroenceph. clin. Neurophysiol., 7, 341-356.ర 